\title{
An Empirical Study about the Effect of Summer Holiday Pension on Physical and Mental Health of the Elderly
}

\author{
Wen $\mathrm{Ge}^{*}$ \\ Management School of Chengdu University of Information \\ Technology \\ Chengdu, China
}

\author{
Tang Shuangshuang \\ Management School of Chengdu University of Information \\ Technology \\ Chengdu, China
}

\begin{abstract}
This article studies the influence of summer holiday pension on the physical and mental health of the elderly. Provide a basis for the healthy lifestyle choice of the elderly and for the care of the elderly by the government or institutions, so as to improve the quality of life of the elderly. Using random sampling method, the SF-36 questionnaire was used to investigate the summer vacation habits and health status of 548 old people in Sichuan Province. Analyze the survey data that using descriptive statistics, internal consistency test, $T$ test, correlation analysis and descriptive statistical. The score in the 9 dimensions of SF-36 scales, the mean value of elderly with summer holiday habit is higher than elderly without. But only the 7 dimensions of the score in General Health, Physical Function, Role-Physical, Bodily Pain, Vitality, Social Functioning and Mental Health, which the difference is statistically significant. The two dimensions of RoleEmotion and Reported Health Transition, which the difference isn't statistically significant. Research discovered that in terms of overall health level, physical fitness, and mental health, elderly people with summer vacation habits are better than elderly people who without.
\end{abstract}

Keywords-Pension pattern; Summer care for the aged; Quality of life; SF-36 scale

\section{INTRODUCTION}

With the global warming, high temperatures and Heat wave weather in summer take on frequent trend. Extreme maximum temperatures break through extremes. A news conference held by the China Meteorological Administration In September 2016

There are 368 stations throughout the country with extreme daily maximum temperature events. Chongqing, south Xinjiang, Middle and lower Yangtze River ,East Sichuan and other places of continuous high temperature 10-15 days, and some areas more than 15 days. Research on the effect of high temperature heat wave on human health is quite extensive. Beginning of the 20th century, there is research on the heat wave and the death of people. Koppe and Others (2004) through the study pointed out that the meteorological disaster caused by the global extreme heat wave has increased the contribution to the mortality of residents In the past 40 years ${ }^{[1]}$. In 2003, Europe has experienced a severe heat wave, in France only 20 days in August, the number of deaths caused by the

Fund Project: The open topic of important research base of Humanities and Social Sciences of Universities and Colleges in Sichuan. Project number: ZHYJ16-ZD01 heat waves is up to 15000 (Hemon etc., 2003) ${ }^{[2]}$, In other European countries, such as Britain, Italy, Spain and Portugal, the number of direct deaths from heat waves is 1000 to 25000 (Bouchama,2004) ${ }^{[3]}$. Theoharatos and others (2010) study that High temperature heat wave has become one of the most important health meteorological disasters affecting residents' health ${ }^{[4]}$. The elderly and infants are the most vulnerable people in the heat wave.

According to statistics, now China has become the most elderly populous country in the world. For the development of the elderly "summer vocation", "Summer Leisure", "summer tourism" has become an important tourist service products On the one hand, All over the use of their own natural climate resources, the development of summer pension projects .on the other hand, Conditional the aged begin to Make the life style of summer vacation popular. In fact, the study on the influence and assessment of the high temperature in summer on the health of the elderly is still weak.is it really beneficial to the Physical and mental health of the elderly in the summer? What aspect is benefit? There is a lack of support for theoretical research. This study uses a mature SF-36 scale, and through the random survey of the elderly in Sichuan province, which purpose is to know the effect of summer heat on physical and mental health of the elderly, it provides evidences for the healthy lifestyle choices of the elderly and for the care of the elderly by the government or institutions.

\section{SURVEY DESIGN}

\section{A. Object and Method of Investigation}

Adopt the principle of randomness, from April to June 2010, Selected 19 districts in downtown Chengdu, Long Quanyi District, Jixian, Santai, etc., and Survey the elderly in these 19 communities. The selection criteria: 50 or over 50 keep Clear consciousness, and the elderly should have the ability to respond. The elderly who can literate can answer the questionnaire on their own. For the elderly who cannot literate, the investigators fill out the questionnaires through interviews. 


\section{B. Investigation Scale}

This study used a more mature health survey scale to measure the health status of the elderly (the MOS item short from health survey, SF-36) medical outcomes study scale was originally developed by Stewartse in 1988. After the improvement and development of the Boston Institute of Health in the United States. Finally, in 1991, the Social Medicine Department of Medical College of Zhejiang University translated this scale into Chinese. Sf-36 scale is widely used in the life quality measurement of the general population, clinical trial effect evaluation, health policy evaluation and so on. And it has been proved by domestic and foreign scholars to have good reliability and validity ${ }^{[5][6]}$.

SF-36 Scale includes 36 entries, 9 dimensions. The nine dimensions are General Health $(\mathrm{GH})$, Physical Functioning (PF), Bodily Pain (BP), Vitality (VT), Social Functioning (SF), Role-Emotional (RE), Mental Health (MH) and Reported Health Transition (HT). Among them, the first 4 dimensions are the comprehensive evaluation of physical health. The fifth eighth dimension is a comprehensive assessment of mental health. The last dimension reflects the health changes compared to a year ago. See TABLE I for details.

TABLE I. CONTENT AND STRUCTURE OF SF-36 SCALE

\begin{tabular}{|l|c|c|c|}
\hline \multirow{4}{*}{$\begin{array}{l}\text { Scale } \\
\text { dimension }\end{array}$} & $\begin{array}{c}\text { Number } \\
\text { of entries }\end{array}$ & $\begin{array}{c}\text { Distribution } \\
\text { of items }\end{array}$ \\
\hline \multirow{3}{*}{ Physical health } & $\mathrm{GH}$ & 5 & SF1,SF11(1-4) \\
\cline { 2 - 4 } & $\mathrm{PF}$ & 10 & SF3(1-10) \\
\cline { 2 - 4 } & $\mathrm{RP}$ & 4 & $\mathrm{SF} 4(1-4)$ \\
\cline { 2 - 4 } & $\mathrm{BP}$ & 2 & SF7,SF8 \\
\hline \multirow{3}{*}{ Mental health } & $\mathrm{VT}$ & 4 & SF9(1,5,7,9) \\
\cline { 2 - 4 } & $\mathrm{SF}$ & 2 & SF6,SF10 \\
\cline { 2 - 4 } & $\mathrm{RE}$ & 3 & SF5(1-3) \\
\cline { 2 - 4 } & $\mathrm{MH}$ & 5 & SF9(2,3,4,6,8) \\
\hline Health change & $\mathrm{HT}$ & 1 & $\mathrm{SF} 2$ \\
\hline
\end{tabular}

This study is based on the SF-36 scale, added 2 questions to measure whether older people have summer habits, first, "Whether it will deliberately arrange summer life", Second, "In the past three years, we have arranged for summer vacations." These two categories are satisfied with summer habits. At the same time, the questionnaire designed the basic information about the surveyed person's gender, age, education level, and whether or not they were retired.

\section{Statistical Analysis Method}

First of all, the application of SPSS22.0 statistical software input data and analysis. Reliability of measurement results using internal consistency analysis, basic data using descriptive statistical analysis. The measurement analysis adopts independent sample t test, and the statistical test is Bilateral test. $\mathrm{P}<0.05$ was considered statistically significant. Meanwhile, it also used the distance analysis in the correlation analysis to understand the correlation between the overall health level and the other nine dimensions.

\section{SURVEY DATA ANALYSIS}

\section{A. General Analysis}

A total of 600 questionnaires were distributed and 569 questionnaires were withdrawn, and missing items are excluded in more than 2 items, there are 548 effective questionnaires and the effective recovery rate is $91.3 \%$. In the survey respondents, there are 237 males, accounting for $43.2 \%$. 311 female, accounting for $56.8 \%$, There are 336 people aged 60 to 79 years old, accounting for $61.3 \%$.

\section{B. Reliability analysis}

Reliability measures the stability and Consistency degree of measurement results, the most used is internal consistency analysis when evaluating reliability. The internal consistency reliability of the Cornbrash's alpha scale was used in this study. It is generally believed that the reliability of Cornbrash's $\alpha$ coefficient above 0.9 is very good, better between $0.8 \sim 0.9$, Acceptable between $0.7 \sim 0.8$.This study was found in the data measurements, the overall Cornbrash's $\alpha$ coefficient of the SF36 is 0.824 . Cornbrash's alpha coefficient of each dimension is shown in TABLE II, Cornbrash's $\alpha$ coefficient is greater than 0.7 , and the internal consistency of the visible scale is better.

TABLE II. CORNBRASH'S A COEFFICIENTS IN EACH DIMENSION OF THE SF-36 SCALE

\begin{tabular}{|c|c|}
\hline Scale dimension & $\begin{array}{c}\text { Cornbrash's } \\
\text { alpha coefficient }\end{array}$ \\
\hline GH & 0.797 \\
\hline PF & 0.798 \\
\hline RP & 0.823 \\
\hline BP & 0.782 \\
\hline VT & 0.798 \\
\hline SF & 0.781 \\
\hline RE & 0.830 \\
\hline MH & 0.809 \\
\hline HT & 0.836 \\
\hline
\end{tabular}

\section{Hypothetical test}

This study used T-Test compared to have summer habits and no summer habits two elderly groups in whether the mean difference of 9 dimensions of sf-36 scale is significant. T-Test results show, the total score (SFTOTAL) of elderly people with summer habits was $(128 \pm 10.20)$, which is higher than the average health score of elderly people without summer heat (119 \pm 11.04$)$. The difference was statistically significant $(\mathrm{P}<0.05$, see TABLE IV). Further analysis found, the average score of the elderly with summer habit is higher than that of the elderly without summer habit. In the score of the 9 dimensions. But only in the 7 dimensions, such as general health $(\mathrm{GH})$, Physical Functioning (PF), physiological function (RP), Bodily Pain (BP), Vitality (VT), Social Functioning (SF), Mental Health $(\mathrm{MH})$, the difference was statistically significant $(\mathrm{P}<0.05$, see TABLE III). There was no statistically significant difference in the two dimensions of Role-Emotional (RE) and Reported Health Transition (HT) (P > 0.05, see TABLE III). 
TABLE III.

COMPARISON OF MEAN VALUES IN EACH DIMENSION OF THE SF-36 SCALE

\begin{tabular}{|c|c|c|c|c|}
\hline $\begin{array}{c}\text { Scale } \\
\text { dimension }\end{array}$ & summer habits & $\begin{array}{c}\text { No summer } \\
\text { habits }\end{array}$ & t & P \\
\hline GH & $67.35 \pm 15.95$ & $56.40 \pm 16.34$ & 4.235 & 0.000 \\
\hline PF & $91.62 \pm 12.18$ & $79.29 \pm 12.89$ & 5.371 & 0.000 \\
\hline RP & $82.69 \pm 18.95$ & $66.27 \pm 19.23$ & 2.864 & 0.005 \\
\hline BP & $85.62 \pm 16.36$ & $76.12+16.01$ & 3.219 & 0.000 \\
\hline VT & $81.77 \pm 9.86$ & $74.62 \pm 11.74$ & 4.425 & 0.000 \\
\hline SF & $113.27 \pm 14.46$ & $102.66 \pm 15.91$ & 4.308 & 0.000 \\
\hline RE & $94.36 \pm 18.04$ & $89.35 \pm 19.24$ & 1.534 & 0.127 \\
\hline MH & $81.66 \pm 10.41$ & $76.80 \pm 11.81$ & 2.903 & 0.011 \\
\hline HT & $54.23 \pm 12.16$ & $50.15 \pm 11.68$ & 4.704 & 0.137 \\
\hline SFTOTAL & $128 \pm 10.20$ & $119 \pm 11.04$ & 4.704 & 0.000 \\
\hline
\end{tabular}

\section{RESUlt Discussion}

\section{A. The influence of summer vacation on physical health of the elderly}

According to the analysis of the previous, In terms of the general health conditions of their own health, whether the physiological function of normal activity ,and because of physiological functions affected by physical health, and in physical pain aspect and in physical pain associated with normal activities or housework. Elderly people with summer habits are obviously better than those without summer habits. Thus, summer retirement is beneficial to the health of the elderly and can improve the quality of life of the elderly. Just as "Nei Jing" demonstrates the climate of man and nature, the appropriateness of the human body and the climate is called "righteousness." And point out "keep healthy, do not be evil, the evil are up, the gas must be false”.

\section{B. The influence of summer vacation on mental health of the elderly}

Mental health refers to the health of people's mental activities and mental states. The Research data show, in terms of personal energy and degree of fatigue, Social functions that the influence of emotion on family and friends and Social activity restrictions. Mental health aspects of emotional adjustment and Cheerful mood. Elderly people with summer habits are obviously better than those without summer habits. Influencing the emotional functions of the completion of various activities due to bad mood. The average value of elderly people with summer habits is higher than those without summer habits. But from the point of statistics, this is not the reason for the impact of the summer. Based on a realistic explanation, maybe elderly people with summer habits are obviously better than those without summer habits in the emotional function, Instead of the changes caused by the summer heat itself.

\section{The influence of summer vacation on the general health of the elderly}

Research data show, the overall health level of the elderly with summer habits is higher than that of the elderly without summer habits. The overall health level includes 9 dimensions, such as Physical Functioning (PF), physiological function (RP), Bodily Pain (BP), Vitality (VT), Social Functioning (SF), RoleEmotional (RE), Mental Health (MH) and Reported Health
Transition (HT). Therefore, using the distance analysis in correlation analysis to further understand the relationship between the overall health level and the other nine dimensions, the results of the analysis are shown in TABLE IV. In nine dimensions, the correlation between RE, HT and the overall health level is weak. This also further explains in TABLE IV. Emotional functions and levels of health changes during one year are not significantly different for elderly people with summer habits and no summer habits. The reason why the general health of the elderly with summer habits are higher than that of the elderly without the summer habits.

TABLE IV. CORRELATION ANALYSIS OF THE OVERALL HEALT H LEVEL AND OTHER DIMENSIONS OF HEALTH IN THE SF-36 SCALE

\begin{tabular}{|c|c|c|c|c|c|}
\hline & GH & PF & RP & BP & VT \\
\hline SFTOTAL & 0.755 & 0.753 & 0.709 & 0.812 & 0.849 \\
\hline & SF & RE & MH & HT & \\
\hline SFTOTAL & 0.830 & 0.429 & 0.715 & 0.276 & \\
\hline
\end{tabular}

\section{CONCLUSION}

To sum up, the research shows. Summer tourism has a good effect on the physical health, mental health and overall health level of the elderly. In old age, because of the social role status, social interaction and so on has changed greatly. It is easy to produce negative emotions and feelings. Summer tourism is not only beneficial to the physical and mental health of the elderly, but also enables the elderly to get out of the tedious housework or boring retirement, and broaden their horizons and expand their living space. At the same time, elderly people who are old and inconvenient, they cannot go out for summer vacation. Therefore, the society and the family should give more attention, In order to ensure the health of the elderly and improve the quality of life of the elderly, the elderly activity room and old-age service agency in the community should take measures to prevent the heatstroke from cooling.

Ranked according to the "Global Age Watch Index", published by the non-governmental organization Help Age International on September 9, 2015, China ranks 52nd. The index is composed of four aspects: income security, health status, personal ability, and Favorable social and environmental conditions. Among them, the health status of the elderly in China is in the middle level, and there is still a large room for improvement. As a result, in Quickly entered the aging of China, To encourage the development of summer tourism products for the elderly, to provide many forms of summer leisure services for the elderly, and the government purchase summer vacation products for the elderly, and to provide summer care for older and inconvenient elderly people is an important guarantee for improving the health status of the elderly and improving the life index of the elderly.

\section{REFERENCES}

[1] C. Koppe, S. Kovats, G. Jendritzky, etc. "Health and global environmental change: heat-waves: risks and responses," Denmark: WMO, 2004.

[2] D. Hemon, E. Jougla. "Estimation de la surmortalite et principles caracteristiques epidemiologiques” Paris: INSERM, 2003, pp. 1-59.

[3] A. Bouchama. "The 2003 European heat wave.” Tensive Care Med, 2004, 30 pp. $1-3$. 
[4] G. Theoharatos, K. Pantavou, A. Mavrakis etc. "Heat waves observed in 2007 in Athens, Greece: synoptic conditions, bioclimatological assessment, air quality levels and health effects.” Environmental Research, 2010, 110(2): pp.152-161.
[5] Yang Xiaoti, Wang Yang, Li Xiujun, etc. "Evaluation of reliability and validity of the SF-36 scale”. Progress in Anatomy Science. 2009, 15(4): pp. 383-385. (In Chinese)

[6] Jin Wenzheng, Yu Huiting. "Reliability and validity of SF-36 scale applied to residents' self -health assessment.” Health Resources in China, 2012, 27(5): pp, 560-561. 